\title{
Crimes sexuais: A outra face da infância e da adolescência
}

\author{
Sexual crimes: The other face of childhood and adolescence
}

Daniela Trevisan Monteiro ${ }^{[a]}$, Fernanda Pires Jaeger ${ }^{[b]}$, Alberto Manuel Quintana ${ }^{[c]}$, Dorian Mônica Arpini ${ }^{[d]}$

\footnotetext{
[a] Psicóloga, mestranda do Programa de Pós-Graduação em Psicologia da Universidade Federal de Santa Maria (UFSM), bolsista Capes, Santa Maria RS - Brasil, e-mail: dtrevisan@ terra.com.br

${ }^{[b]}$ Psicóloga, mestre em Psicologia Social e da Personalidade, docente do curso de Psicologia da Pós-graduação Criança e Adolescente em Situação de Risco, do Centro Universitário Franciscano (UNIFRA), Santa Maria, RS - Brasil, e-mail: fpjaeger@unifra.br

${ }^{[c]}$ Psicólogo, doutor em Ciências Sociais (Antropologia Clínica), professor do curso de Psicologia e dos Programas de Pós-Graduação em Psicologia (Mestrado) e Enfermagem (Mestrado) da Universidade Federal de Santa Maria (UFSM), Santa Maria, RS - Brasil, e-mail: albertoq@ccsh.ufsm.br

${ }^{[d]}$ Psicóloga, doutora em Psicologia Social, professora do Departamento de Psicologia e do Programa de Pós-Graduação em Psicologia da Universidade Federal de Santa Maria (UFSM), Santa Maria, RS - Brasil, e-mail: monica.arpini@gmail.com
}

Recebido: $26 / 05 / 2011$ Received: 05/26/2011

Aprovado: 04/11/2011 Approved: 11/04/2011

\section{Resumo}

Por muito tempo, a infância foi retratada em um lugar periférico. Não existia proteção à criança, o que resultava no aumento das probabilidades de abandono, atos comuns de infanticídio e abusos físicos e sexuais. Esta pesquisa traz como tema crianças e adolescentes vítimas de crimes sexuais. 0 objetivo geral desta pesquisa é caracterizar os crimes sexuais sofridos na infância e adolescência a partir dos processos registrados na Delegacia de Proteção a Criança e Adolescente de Santa Maria. Essa caracterização dar-se-á por meio de uma pesquisa quantitativa, social Exploratória de Análise Documental. Foram registradas 73 denúncias no ano de 2007. Atentado violento ao pudor foi o crime mais cometido, com $56,16 \%$, seguido de estupro com 19,18\%. Também foi possível perceber que os crimes sexuais ocorrem com prevalência em situações intrafamiliares, sendo o adulto de confiança da criança um dos maiores abusadores. Dessa forma, os abusos acontecem em sua maior parte nos locais de convívio da vítima. A violência de gênero também é apontada, apresentando uma diferença significativa entre crimes contra o sexo feminino, com $77,03 \%$. Observa-se, igualmente, que as mães aparecem como as mais presentes no ato de realizar a denúncia. Assim, é preciso considerar que toda situação de abuso é uma experiência traumática e que a criança revive essa situação quando realiza sua denúncia.

Palavras-chave: Abuso da criança. Infância. Adolescência.

\section{Abstract}

For a long time, childhood was portrayed in a peripheral locus. There was no protection to the child, which resulted in the increase of probabilities of abandonment and common acts of infanticide and physical and sexual abuse. This research has as its theme the children and adolescents who are victims of sexual crimes. Many accusations of sexual crimes continue weekly reaching the Police Station of Protection of Childhood and Adolescence. The main objective of this research is characterizing the sexual crimes suffered in childhood based on the cases registered in Police Station of Protection of the Child and Adolescent of Santa Maria. This characterization will occur through a quantitative research and social Exploratory Documentary Analysis. Seventy-three (73) denouncements were registered in 2007. Violent sexual assault was the most committed crime, with $56.16 \%$, followed by rape, with $19.18 \%$. It was also possible to notice that sexual crimes occur with prevalence in intra-family situations, and the adult who the child trusts the most is one of the most frequent abusers. This way, abuse happens in most of the sites which are familiar to the victim. Gender violence is also seen, showing a significant difference between crimes 
against women, with $77.03 \%$. It is also noticed that mothers appear to be the ones most present in the act of performing the denouncements. So, it is necessary considering that any situation of abuse is a traumatic experience and that the child experiences this entire situation again when it is denounced.

Keywords: Child abuse. Childhood. Adolescence.

\section{Introdução}

Podemos falar que a invenção da infância, segundo Ariès (1981), provida de cuidados, proteção e afetividade é algo ainda recente. A criança, por inúmeras vezes na nossa história, foi considerada como objeto dos adultos. A passagem da criança de objeto para sujeito dá-se com a evolução das ciências, o que, de certa forma, incentivou o surgimento de legislações protetivas à infância. Essa passagem vinha sendo construída já há algum tempo, principalmente com o advento da modernidade e com todas as mudanças no cenário familiar e social; mas é a partir do Estatuto da Criança e do Adolescente (1990) que essa visão se materializa. A criança deixa de ser considerada um objeto e passa a ser considerada um sujeito que possui deveres e direitos. Porém, apesar de todos os avanços e mudanças, a criança, por vezes, torna-se objeto nas mãos de adultos que cometem crimes sexuais contra ela.

De acordo com Ariès (1981), a infância é retratada hoje como uma fase de intenso crescimento físico e emocional. Os diversos aspectos do desenvolvimento da criança compreendem o crescimento corpóreo, os câmbios psicológicos e emocionais e a adaptação social. Sabe-se que as diretrizes do desenvolvimento da criança envolvem também circunstâncias ambientais. Ocorrem nessa fase modificações psíquicas que acompanharão a criança no decorrer de sua vida, fazendo parte de sua personalidade. Uma situação de violência física e/ou emocional pode acarretar traumas, momentâneos ou permanentes, devendo ser demandado um olhar diferenciado nessa fase tão peculiar. (Fereczi, 1992; Gabel, 1997). Ao longo dos séculos, o sentimento da infância foi se apresentando até chegar à forma de hoje. Na cultura medieval até o século XI, não havia uma representação da infância, algo que pudesse separar a criança do adulto; elas eram representadas com o mesmo tipo de corpo do adulto - "adulto em miniatura". Foi apenas a partir do século XII que surgiram as primeiras representações da infância advindas da cultura religiosa por meio dos "anjos adolescentes"; essas representações compreendem a terceira infância, ou seja, crianças a partir dos 10 anos. No século XIII, as crianças eram representadas sem sexo, mais propriamente, apresentando a imortalidade da alma. As primeiras representações de crianças em suas proporções normais surgem com a imagem da Virgem Maria e o menino Jesus.

Marcílio (1998) ressalta que o surgimento da percepção da existência da infância, no decorrer do século XIII, não significou melhores condições de vida para a criança. Na tradição portuguesa, as crianças abandonadas tornavam-se objetos de caridade na "Roda dos Expostos" ou nas Casas de Misericórdias. As crianças expostas, por assim dizer, eram rejeitadas pelas suas mães, expostas na sociedade e postas "na caridade". 0 abandono garantia o anonimato de moças que engravidavam antes do casamento e protegia a moral da família. A pobreza, doença do pai ou da mãe, assim como bebês doentes ou deficientes e pais não casados também eram causas do abandono. Nas Casas da Roda dos Expostos, um terço das crianças abandonadas não completavam 7 anos, por causa da alta taxa de mortalidade infantil. A criança abandonada era destinada à categoria de excluída, marginalizada, com dificuldades para a construção de sua identidade e desenvolvimento saudável.

Freitas (1997) ressalta que, em 1823, a expressão "criança" surge pela primeira vez a partir da construção do Estado, nas discussões sobre a instrução e ensino aos moradores do Império. É a partir das primeiras instituições de ensino de nível superior que a infância ganha maior importância, principalmente na área da medicina. Esta assume os cuidados da criança por meio do conhecimento especializado e da higienização da família e da sociedade. No período 1836 e 1870, das teses apresentadas 
na Faculdade de Medicina do Rio de Janeiro, 81 eram voltadas ao tema da infância, com enfoque na prostituição infantil, frequência escolar, higiene dos escravos, infanticídio e mortalidade infantil. É somente no início do século XIX que a preocupação com a infância abrange áreas não estudadas pela medicina, envolvendo outros setores sociais.

Parafraseando Vorcaro (2004), na origem latina infans, infantis refere-se aos que não falam. Esse termo denota uma estrutura inacabada. Infantia possui referência com a falta de eloquência, dificuldade em explicar-se. 0 termo "infância" vai além de uma condição orgânica de um estágio de aquisição da linguagem; demonstra, também, uma condição de submissão jurídica. Condição de um falante sem legitimidade ou reconhecimento social. Provindo da mesma raiz latina, o termo Infantaria aplica-se à soldados adestrados; enquanto que Infame, aos desonrados. Já o termo "criança" possui sua origem em creantia e se refere ao animal que está sendo criado. 0 caráter da criança, a partir desse ato criativo de outro que a inventa, proporciona o significado desta enquanto única e singular. Essa configuração importante coloca a condição de criança em um caráter de submissão a uma especularidade, a um estado de subordinação à alteridade.

Juridicamente, as discussões iniciais sobre a infância perpassaram a limitação para a responsabilidade penal. No decorrer das discussões, o Estatuto da Criança e do Adolescente (2007) materializa-as sob forma de lei. Este preconiza, a partir do artigo terceiro, que a criança dispõe de proteção integral. Ela possui todos os direitos fundamentais inerentes à pessoa humana, sendo assegurados o desenvolvimento físico, mental, moral, espiritual e social em condições de liberdade e dignidade. É também por meio do Estatuto que se materializam os direitos da criança; direito à liberdade, ao respeito, à dignidade como pessoa humana em processo de desenvolvimento e como sujeito de direitos civis.

Tais direitos, porém, são violados quando a criança se torna vítima de algum tipo de crime. Segundo Guerra (1998), essa violência é justamente a negação dos direitos considerados universais: liberdade, igualdade e vida.

De acordo com Strey (2004), todo comportamento que vise à satisfação própria em detrimento de outra pessoa é considerado violência. Dessa forma, os crimes sexuais se enquadram facilmente no que chamamos de violência, pois eles ocorrem por meio da manipulação e submissão de outra pessoa, onde o seu executor sente satisfação em realizá-lo.

A criança que é abusada sexualmente tende, segundo Gabel (1997), a apresentar dificuldades em sua evolução psicoafetiva e sexual. São afetadas, também, as identificações consideradas saudáveis e que ela poderia construir, impedindo que a adolescência seja um período de requestionamento construtivo.

Esse mesmo autor refere que, quando se trata de abuso sexual intrafamiliar, os danos psicológicos causados à criança são ainda mais intensos. Isso porque o elo que a criança possui com seu abusador é também um fator determinante. Quando o abusador é o próprio pai, por exemplo, a criança sente-se confusa em relação às imagens parentais e o pai deixa de desempenhar seu papel protetor e representante da lei, gerando uma distorção que confunde a criança (Ferenczi, 1992).

Faleiros e Faleiros (2001) retratam que a violência sexual contra a criança cometida por algum familiar ou conhecido se constitui num espaço de silêncio, segredo e sigilo. Os pactos de silêncio são mantidos pelos familiares, amigos, vizinhos, comunidades e profissionais que acobertam desqualificando as manifestações verbais e não verbais da criança vítima do abuso, negando evidências e sinais, graças a interesses e temores de diversas ordens (rupturas familiares, perdas, temores diante da justiça, entre outros)

Diante do abuso sexual, de acordo com Gabel (1997), a criança pode reagir sob forma de estresse que se apresenta como agitação ou por meio do choque ou recuo, anestesia afetiva seguida por terror, regressões e/ou manifestações psicossomáticas. A criança em choque, às vezes acompanhada por mutismo, só consegue contar o que lhe aconteceu depois de sentir confiança. Assim, para que a criança sinta-se segura, é preciso que se beneficie de um ambiente suficientemente bom e que lhe permita confiar em um adulto. É por isso que, na maioria das vezes, os abusos sexuais que ocorrem fora da família são denunciados com mais frequência pela criança.

Autores como Dobke (2001) e Furniss (1993) conceituam que o abuso sexual ocasiona nas vítimas danos primários e secundários. Os danos primários são causados pelas etapas de desenvolvimento do abuso, aquelas que compreendem a fase de sedução, da interação sexual abusiva e do segredo. Já os danos secundários são causados por fatores diversos e subsequentes ao abuso, são eles: estigmatização 
social, traumatização secundária no processo interdisciplinar, traumatização secundária no processo família-profissional, traumatização secundária no processo familiar, traumatização secundária no processo individual.

A violência sexual, de acordo com Faleiros e Faleiros (2001), causa grave violação das garantias de direitos sociais e individuais. Violando a integridade física da criança, também é violada sua integridade psicológica, seu direito ao respeito, à dignidade e à sexualidade vivida de forma responsável e protegida.

Diante da contraditória questão de a criança ser considerada um sujeito de direitos e, em contrapartida, encontrar-se violada em seus direitos, é que esta pesquisa se propõe a refletir sobre o tema da criança e do adolescente vítimas de crimes sexuais. 0 caminho que será percorrido encontra-se focado em dados quantitativos de denúncias de crimes sexuais dentro da Delegacia de Proteção à Criança e Adolescente (DPCA). 0 objetivo geral foi caracterizar os crimes sexuais sofridos na infância a partir dos processos registrados na Delegacia de Proteção a Criança e Adolescente de Santa Maria. Os objetivos específicos buscaram quantificar dados existentes nos processos relativos a crimes sexuais sofridos na infância e adolescência, tais como: natureza do Crime (tentativa de estupro, estupro, atentado violento ao pudor, ato obsceno, corrupção de menores, importunação ofensiva ao pudor, posse sexual mediante fraude e sedução); número de denúncias realizadas mensalmente; quem são os agressores; locais onde acontecem os crimes sexuais; idade e sexo das crianças que sofreram crime sexual; classe social; quem leva a criança e/ou adolescente para realizar a denúncia.

\section{Metodologia}

Para contemplar os objetivos propostos, a pesquisa foi realizada em caráter quantitativo; sendo esta uma pesquisa social Exploratória de Análise Documental. Segundo May (2004), os documentos não existem isolados, eles precisam ser colocados em uma estrutura teórica para que seu conteúdo seja compreendido.

Para a realização do estudo, foram analisados os processos de crianças e adolescentes até 18 anos, vítimas de crimes sexuais que prestaram depoimento na Delegacia de Proteção à Criança e Adolescente de Santa Maria, RS.

Os documentos pesquisados contemplam os processos arquivados na Delegacia de Proteção à Criança e Adolescente do ano de 2007. Os documentos consultados são considerados, de acordo com Gil (1991), documentos "de primeira mão" em função de não terem recebido nenhum tratamento analítico.

Foram coletados os seguintes dados constantes nos processos: natureza do crime, entre estas: tentativa de estupro, estupro, estupro presumido, atentado violento ao pudor, ato obsceno, importunação ofensiva ao pudor, entre outros; número de denúncias realizadas mensalmente; quem são os agressores; locais onde acontece o crime sexual; idade e sexo das crianças e adolescentes que sofreram crime sexual; e quem leva a criança e/ou adolescente para realizar a denúncia.

Após a coleta dos dados, estes foram analisados quantitativamente, a partir da análise de conteúdo proposta por Bardin (1997). Segundo May (2004), na análise quantitativa, o analista quantitativo procede às categorias dos dados para que eles possam ser avaliados. As palavras ou frases que constam nos documentos tornam-se números. O número de vezes que uma palavra se apresenta no documento é um indicador de sua significação, uma estratégia que auxilia na confiabilidade dos dados classificados.

\section{Apresentação e discussão dos resultados}

Mesmo com a Declaração Universal dos Direitos das Crianças e Adolescentes, em 1959, e com o Estatuto da Criança e do Adolescente, em 1990, ainda hoje é intensa a violência praticada contra crianças e adolescentes. Jaeger et al. (2004) ressaltam ainda que a própria família, que deveria ser a responsável pela proteção de sua criança, aparece como fator de risco à vida delas. 0 próprio lar é fonte de violência.

Nas denúncias arquivadas na Delegacia de Proteção à Criança e Adolescente, em relação aos crimes sexuais, a violência sexual se destaca por seus 73 casos ocorridos no ano de 2007 e pelos relatos feitos pelas crianças vítimas de abuso sexual (Quadro 1). 
Quadro 1 - Tipos de crimes sexuais cometidos contra a criança e o adolescente em relação ao período de 2007

\begin{tabular}{|c|c|c|c|c|c|c|c|c|c|c|c|c|c|c|}
\hline \multirow{2}{*}{$\begin{array}{l}\text { Tipos de crimes sexuais } \\
\text { cometidos contra a } \\
\text { criança e o adolescente }\end{array}$} & \multicolumn{14}{|c|}{ Período - 2007} \\
\hline & Jan & Fev & Mar & Abr & Maio & Jun & Jul & Ago & Set & Out & Nov & Dez & Total & $\%$ \\
\hline $\begin{array}{l}1 \text { - Atentado Violento } \\
\text { ao Pudor }\end{array}$ & 6 & 3 & 8 & 2 & 1 & 3 & 3 & 3 & 4 & 1 & 3 & 4 & 41 & 56,16 \\
\hline 2 - Ato Obsceno & - & - & - & 1 & - & - & - & - & - & - & - & - & 1 & 1,37 \\
\hline 3 - Art. 241 do ECA* & - & - & - & - & - & - & - & - & 1 & - & - & - & 1 & 1,37 \\
\hline 4 - Art. 244 - A do ECA* & 2 & - & - & - & - & 1 & - & - & - & 1 & - & - & 4 & 5,48 \\
\hline 5 - Estupro & - & 2 & 1 & 2 & - & 1 & 1 & 3 & 1 & 1 & 2 & - & 14 & 19,18 \\
\hline 6 - Estupro Tentado & - & - & - & 2 & 1 & - & - & 1 & - & - & - & - & 4 & 5,48 \\
\hline 7 - Estupro Presumido & - & - & - & 2 & - & 1 & - & - & - & - & - & - & 3 & 4,10 \\
\hline $\begin{array}{l}8 \text { - Importunação Ofen- } \\
\text { siva ao Pudor }\end{array}$ & - & - & 1 & - & 1 & - & - & - & - & - & - & - & 2 & 2,74 \\
\hline 9 - Roubo com Estupro & - & - & 1 & - & - & - & - & - & - & - & - & - & 1 & 1,37 \\
\hline $\begin{array}{l}10 \text { - Art. } 243 \text { do ECA* e } \\
\text { Atentado Violento } \\
\text { ao Pudor }\end{array}$ & - & - & 1 & - & - & - & - & - & - & - & - & - & 1 & 1,37 \\
\hline $\begin{array}{l}11 \text { - Art. } 243 \text { do ECA e } \\
\text { Estupro }\end{array}$ & - & - & - & - & - & - & - & - & 1 & - & - & - & 1 & 1,37 \\
\hline TOTAL & 8 & 5 & 12 & 9 & 3 & 6 & 4 & 7 & 7 & 3 & 5 & 4 & 73 & $100 \%$ \\
\hline$\%$ & 10,96 & 6,85 & 16,44 & 12,33 & 4,10 & 8,22 & 5,48 & 9,59 & 9,59 & 4,10 & 6,85 & 5,48 & $100 \%$ & \\
\hline
\end{tabular}

Nota: Art. 241 do ECA: Fotografar ou publicar cena de sexo explícito ou pornográfica envolvendo criança ou adolescente. Art. 244A do ECA: Submeter criança ou adolescente à prostituição ou à exploração sexual.

Art. 243 do ECA: Vender, fornecer ainda que gratuitamente ou entregar, de qualquer forma, a criança ou adolescente, sem justa causa, produtos cujos componentes possam causar dependência física ou psíquica, ainda que por utilização indevida.

Fonte: Dados da pesquisa.

Destacam-se, no Quadro 1, os 56,16\% casos cometidos em relação à Atentado Violento ao Pudor, seguido de 19,18\% casos de Estupro. Em relação aos meses em que aconteceram crimes sexuais, a discrepância não é tão grande; mas é no período de março que ocorre o maior número de casos. São doze denúncias, ou seja, 16,44\% das denúncias de crime sexual ocorridas no ano de 2007.

A violência sexual, de acordo com Gabel (1997), supõe uma disfunção/desordenação em três diferentes níveis. Primeiro, o abuso do poder exercido pelo adulto, que é mais forte, sobre a criança, que é mais fraca; segundo, a criança confia no adulto que deveria ser o seu protetor, mas não é correspondida nessa confiança; e por último, o uso inadequado da sexualidade da criança, tirando o direito de propriedade do seu corpo.

É importante ressaltar que o atentado violento ao pudor e o estupro, mesmo nas suas formas básicas (violência presumida), são considerados crimes hediondos, segundo Franco (2005), mesmo que da violência não resulte lesão corporal grave ou morte da vítima, basta ter ocorrido sobre grave ameaça ou violência real. Na execução da pena, o regime deve ser integralmente fechado.

Nota-se, a partir do Quadro 2, que os crimes sexuais possuem sua prevalência nas situações intrafamiliares. Padrastos e tios apresentam os maiores índices nesse caso, seguido pelos pais. São $14,1 \%$ entre os casos em que o padrasto é o acusado e $11,27 \%$ nos casos em que o tio é apontado como o acusado. Apesar de estar em menor número, os casos onde o pai é o abusador $(5,63)$, é igualmente significativo se considerarmos que, nesse caso, os danos psicológicos à criança e ao adolescente são maiores graças ao grau de confiança que se estabelece entre um filho e seu pai. 
Quadro 2 - Tipos de crimes sexuais cometidos contra a criança e o adolescente em relação aos acusados pelos crimes

\begin{tabular}{|c|c|c|c|c|c|c|c|c|c|c|c|c|c|c|c|}
\hline \multirow[b]{2}{*}{$\begin{array}{l}\text { Tipos de crimes } \\
\text { sexuais cometidos } \\
\text { contra a criança } \\
\text { e adolescente }\end{array}$} & \multicolumn{15}{|c|}{ ACUSADOS } \\
\hline & ๘ี & 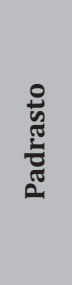 & $\stackrel{\ominus}{\rightleftarrows}$ & 㝌 & 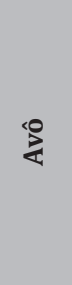 & 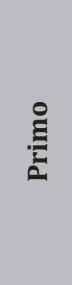 & 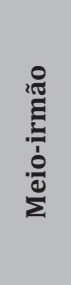 & 宽 & 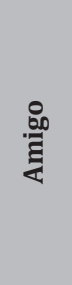 & 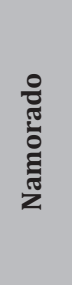 & 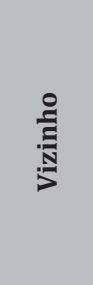 & 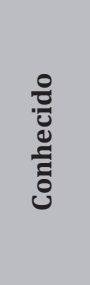 & 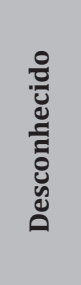 & 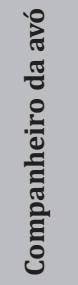 & 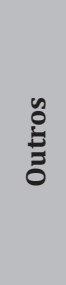 \\
\hline $\begin{array}{l}1 \text { - Atentado Violento ao } \\
\text { Pudor }\end{array}$ & 4 & 7 & 4 & 1 & - & 3 & 2 & - & 1 & - & 11 & 3 & 2 & 1 & 1 \\
\hline 2 - Ato Obsceno & - & - & - & - & - & - & - & - & - & - & 1 & - & - & - & - \\
\hline 3 - Art. 241 do ECA & - & - & - & - & - & - & - & - & - & 1 & - & - & - & - & - \\
\hline 4 - Art. 244 - A do ECA & - & - & - & - & - & - & - & - & - & - & - & 1 & 1 & - & 2 \\
\hline 5 - Estupro & - & 3 & 4 & - & 1 & - & - & - & - & 2 & 1 & 1 & 1 & - & - \\
\hline 6 - Estupro Tentado & - & - & - & - & - & - & - & 1 & - & - & 1 & 1 & - & 1 & - \\
\hline 7 - Estupro Presumido & - & - & - & - & - & - & - & - & - & 3 & - & - & - & - & - \\
\hline $\begin{array}{l}8 \text { - Importunação Ofensi- } \\
\text { va ao Pudor }\end{array}$ & - & - & - & - & - & - & - & - & - & - & 1 & - & 1 & - & - \\
\hline 9 - Roubo com Estupro & - & - & - & - & - & - & - & - & - & - & - & - & 1 & - & - \\
\hline $\begin{array}{l}10 \text { - Art. } 243 \text { do ECA e } \\
\text { Atentado Violento ao } \\
\text { Pudor }\end{array}$ & - & - & - & - & - & - & - & - & - & - & - & 1 & - & - & - \\
\hline $\begin{array}{l}11 \text { - Art. } 243 \text { do ECA e } \\
\text { Estupro }\end{array}$ & - & - & - & - & - & - & - & - & - & - & - & 1 & - & - & - \\
\hline TOTAL* & 4 & 10 & 8 & 1 & 1 & 3 & 2 & 1 & 1 & 6 & 15 & 8 & 6 & 2 & 3 \\
\hline$\%$ & 5,63 & 14,1 & 11,27 & 1,41 & 1,41 & 4,23 & 2,82 & 1,41 & 1,41 & 8,45 & 21,13 & 11,27 & 8,45 & 2,82 & 4,23 \\
\hline
\end{tabular}

Nota: *Há um processo que não foi encontrado e outro em que não constava o depoimento, completando, assim, 73 crimes sexuais cometidos contra a criança e o adolescente. Eles se referem a Atentado Violento ao Pudor e Estupro, respectivamente.

Fonte: Dados da pesquisa.

Segundo Saffiotti (2004), é na família, na escola e em outras instituições que se ensina a criança a não aceitar convites, doces ou outros presentes de estranhos. É menos comum quando a criança ou adolescente sofre violência por parte de estranhos; geralmente os agressores são amigos ou conhecidos, incluindo membros da própria família. No caso dos crimes sexuais, isso fica claro, pois, em sua maior parte, predominam os parentes como acusados.

Esse mesmo autor considera que o pai é o adulto masculino no qual a criança mais confia, daí a magnitude e a profundidade do trauma psíquico. Muitas vezes, o abuso inicia com a sedução; o pai dá maior atenção à filha, mais presentes, mais passeios, etc. 0 interesse vai aumentando até que se iniciem as carícias sexualizadas. Dependendo da idade da criança, ela não sabe diferenciar entre um e outro tipo de carícia, sendo incapaz de perceber o momento da mudança.
Considerando a sexualidade da mulher difusa por todo o corpo e a sexualidade infantil não genitalizada, as carícias abrangem todo o corpo proporcionando prazer à vítima. Acompanhada da sensação de prazer em ser acariciada, existe também a culpa, o que, na perspectiva de Lamour (1997), será um dos aspectos que leva ao isolamento e ao silêncio das vítimas.

Segundo Mess (2001), a culpa está presente na mesma medida que o trauma; quando a vítima relaciona o abuso sexual que sofre de seu pai a uma resposta por causa da sua sedução. Considerando o abuso como efeito da sedução, o pai sai de seu lugar de protetor e se configura o trauma (Ferenczi, 1992; Lamour, 1997; Royer, 1997). Sendo assim, a culpa é reflexo da crença do envolvimento do seu desejo, tirando o pai de seu lugar de protetor, quer dizer que a criança assume parte da autoria, sentindo-se responsável pelo ato, o que é parte da distorção estabelecida. Quando a vítima não 
percebe o pai abusador respondendo a sua sedução, então a culpa será atribuída a algo ou alguém que não ela.

A culpa, de acordo com Dobke (2001), é o principal fator psicológico que conduz o abuso sexual infantil à síndrome do segredo, seguida pela negação e a dissociação. A criança se sente culpada, pois se encontra ligada à interação abusiva e procede da participação passiva da situação de abuso. 0 sentimento de culpa da criança se origina a partir de seu equivocado senso de responsabilidade pelo abuso, levando-a a manter segredo. Na negação, é criada uma estrutura que nega a realidade da experiência impedindo a vítima de ver o abuso como abuso. E na dissociação, a vítima divide o fato real do abuso sexual dos sentimentos que ele gera, fazendo com que as emoções relacionadas ao abuso não interfiram na sua vida.

O silêncio, segundo Mess (2001), cumpre a função de evitar o perigo que a revelação pode trazer para a vítima ou para a sua família. A ameaça frequentemente realizada pelo autor da violência acaba por ser aceita inconscientemente pela vítima, pois, segundo a autora, a vítima considera que existe algo pior do que manter relações sexuais com o pai que é perder o pai simbólico que até então foi mantido afastado da cama. Nesse sentido, a autora aponta que a revelação pode ocorrer quando não existe mais essa divisão paterna. Assim, a vítima acaba por delatar o pai quando sua defesa até então mantida se enfraquece. Ou, em outros casos, quando alguém surge e consegue significar proteção encorajando a criança ou adolescente a revelar a situação abusiva.

Segundo Viaux (1997), o silêncio deve ser compreendido como parte da dinâmica que se estabelece na situação de abuso, não significando que as coisas estão bem, pelo contrário, ele responde ao temor das ameaças, da culpa e do medo do rompimento das relações familiares (Arpini et al., 2010).
Podemos observar que, entre os abusos extra-familiares, são os vizinhos que apresentam maior prevalência. São 21,13\% seguidos por pessoas conhecidas da vítima, que apresentam 11,27\%.

Quando se trata de abuso extrafamiliar, segundo Dobke (2001), a síndrome do segredo não costuma ocorrer com tanta força, nessas situações se obtém a cooperação da família e da vítima para a revelação. Portanto, o abuso extrafamiliar não é de difícil comprovação, diferentemente do abuso intrafamiliar. Mesmo sendo o abuso extrafamiliar mais fácil de ser comprovado, uma vez que ele tem mais possibilidades de ser revelado num tempo mais breve, não significa que tal abuso não traga danos psicológicos severos.

É claro que, no caso de um abuso intrafamiliar, por ser um pai o abusador, os danos sofridos se acentuam; mas, mesmo nos casos em que o adulto autor da violência não é da família, há um grau de confiança depositado pela criança e que não é correspondido, transgredindo os limites de sua confiança e do seu corpo. 0 sofrimento psicológico torna-se maior se o abuso já vem acontecendo e a criança sente vergonha de contar. Muitas vezes, como observado nos casos denunciados na Delegacia de Proteção à Criança e Adolescente, a denúncia só acontece quando a vítima já é adolescente. Nessa etapa, os danos psicológicos sofridos já são muitos (e alguns irreversíveis) e o tratamento psicológico se faz muito necessário.

Da mesma forma que a criança deposita sua confiança no adulto, ela também acaba se sentindo protegida nos lugares que costuma frequentar. Sua casa e a casa de parentes são considerados lugares seguros para a sua convivência. Porém, nos casos em que ocorreram violências, os locais, ao invés de serem protetivos, tornaram-se lugares que ofereceram maior risco para a criança (Quadro 3).

Quadro 3 - Tipos de crimes sexuais cometidos contra a criança e o adolesdente em relação aos locais em que ocorrem esses crimes

\begin{tabular}{|c|c|c|c|c|c|c|c|c|c|c|c|c|}
\hline \multirow[b]{3}{*}{$\begin{array}{c}\text { Tipos de crimes sexuais } \\
\text { cometidos contra a criança } \\
\text { e o adolescente }\end{array}$} & & & & & & & & & & & (Co & hua \\
\hline & \multicolumn{12}{|c|}{ LOCAIS } \\
\hline & 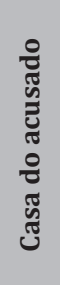 & 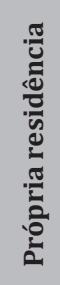 & 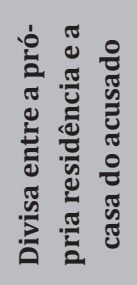 & 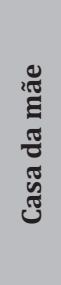 & $\begin{array}{l}\tilde{y} \\
\tilde{0} \\
\tilde{0} \\
\tilde{0} \\
\tilde{\sigma} \\
\tilde{y} \\
\tilde{J}\end{array}$ & $\begin{array}{l}\tilde{0} \\
\stackrel{0}{0} \\
\tilde{0} \\
\frac{0}{0} \\
\tilde{J} \\
\tilde{J}\end{array}$ & 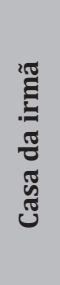 & 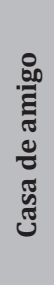 & 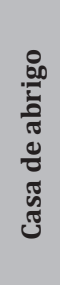 & 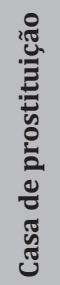 & $\frac{\stackrel{0}{0}}{\stackrel{0}{0}}$ & 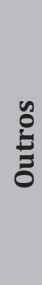 \\
\hline 1 - Atentado Violento ao Pudor & 9 & 15 & 2 & 3 & 3 & - & - & 1 & 1 & - & 4 & 2 \\
\hline 2 - Ato Obsceno & - & - & - & - & - & - & - & - & - & - & 1 & - \\
\hline
\end{tabular}

Psicol. Argum. 2012 jul./set., 30(70), 463-476 
Quadro 3 - Tipos de crimes sexuais cometidos contra a criança e o adolesdente em relação aos locais em que ocorrem esses crimes

\begin{tabular}{|c|c|c|c|c|c|c|c|c|c|c|c|c|}
\hline \multirow[b]{2}{*}{$\begin{array}{c}\text { Tipos de crimes sexuais } \\
\text { cometidos contra a criança } \\
\text { e o adolescente }\end{array}$} & \multicolumn{12}{|c|}{ LOCAIS } \\
\hline & 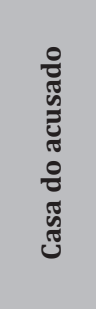 & 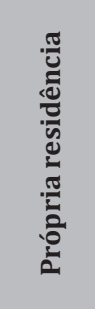 & 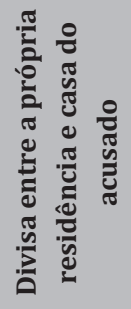 & 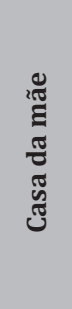 & 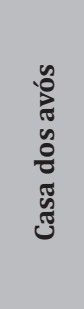 & 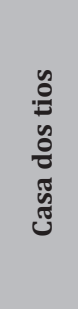 & 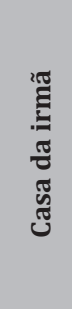 & 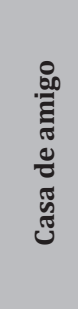 & 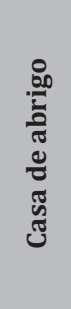 & 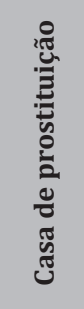 & 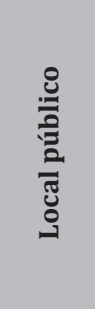 & $\stackrel{n}{E}$ \\
\hline 3 - Art. 241 do ECA & - & - & - & - & - & - & - & - & - & - & - & 1 \\
\hline 4 - Art. 244 - A do ECA & - & - & - & - & - & - & - & - & - & 4 & - & - \\
\hline 5 - Estupro & 2 & 7 & - & - & 1 & 1 & - & 2 & - & - & - & 1 \\
\hline 6 - Estupro Tentado & - & 1 & - & - & - & - & 1 & - & - & - & 2 & - \\
\hline 7 - Estupro Presumido & 2 & 1 & - & - & - & - & - & - & - & - & - & - \\
\hline $\begin{array}{l}8 \text { - Importunação Ofensiva ao } \\
\text { Pudor }\end{array}$ & - & - & - & - & - & - & - & - & - & - & 2 & - \\
\hline 9 - Roubo com Estupro & - & - & - & - & - & - & - & - & - & - & 1 & - \\
\hline $\begin{array}{l}10 \text { - Art. } 243 \text { do ECA e Atentado } \\
\text { Violento ao Pudor }\end{array}$ & - & - & - & - & - & - & - & - & - & - & - & 1 \\
\hline 11 - Art. 243 do ECA e Estupro & 1 & - & - & - & - & - & - & - & - & - & - & - \\
\hline TOTAL* & 14 & 24 & 2 & 3 & 4 & 1 & 1 & 3 & 1 & 4 & 10 & 5 \\
\hline$\%$ & 19,44 & 33,33 & 2,78 & 4,17 & 5,56 & 1,39 & 1,39 & 4,17 & 1,39 & 5,56 & 13,89 & 6,94 \\
\hline
\end{tabular}

Nota: *Há um processo não encontrado, completando, assim, 73 crimes sexuais cometidos contra a criança e o adolescente. Ele se refere a Atentado Violento ao Pudor.

Fonte: Dados da pesquisa.

Observa-se, no Quadro 3, que a maior parte dos crimes de violência sexual contra a criança/adolescente ocorreu nos lugares de convívio da vítima. A sua própria residência, lugar que deveria oferecer segurança aparece com $33,33 \%$ dos casos denunciados. Ao todo, são 45,84\% dos casos denunciados que ocorrem nas casas de familiares e na sua própria residência. Número significativo e preocupante, pois a família, provedora de cuidados, torna-se a maior vilã para a criança/adolescente vítima de abuso sexual.

A criança também deposita sua confiança nos adultos que fazem parte do seu dia a dia, como por exemplo: amigos de seus pais, muitas vezes vizinhos ou algum cuidador em quem os pais depositam confiança para entregar seus filhos. Esses também aparecem com números preocupantes (vide Quadro 2 ), o que novamente nos faz constatar que a maioria dos casos de abuso sexual ocorre entre aqueles em quem a criança já tem uma relação e deposita confiança. Acontece que, nos casos denunciados,
$19,44 \%$ dos crimes ocorrem na casa do acusado. Uma outra situação que aparece nos relatos das vítimas refere-se à "compra" da confiança da criança. Muitas vezes, o adulto abusador oferece doces, brinquedos ou até dinheiro à vítima, que, perante a sua inocência, acaba por aceitar.

Entre os locais públicos, aparece nos relatos os locais de passagem das vítimas. 0 caminho da escola, a volta para a casa ou a ida ao mercado aparecem como locais de risco e somam $13,89 \%$ de crimes sexuais cometidos contra a criança e/ou adolescente.

No Quadro 4, nota-se que a maior porcentaem refere-se à idade entre 12 e 15 anos; são 36,49\%. Nesse grupo encontram-se em sua maior parte, crimes de estupro. Nos depoimentos observados nos registros, foi possível perceber que a maioria desses crimes ocorreu entre adolescentes que namoravam meninos maiores de idade, com ou sem o consentimento dos pais. Com o fim do namoro, quando consentido pelos pais, ou com o descobrimento dos pais que não consentiam o namoro, foi 
Quadro 4 - Tipos de crimes sexuais cometidos contra a criança e o adolescente em relação à idade

\begin{tabular}{|c|c|c|c|c|c|}
\hline \multirow{2}{*}{$\begin{array}{l}\text { Tipos de crimes sexuais cometidos contra a } \\
\text { criança e o adolescente }\end{array}$} & \multicolumn{5}{|c|}{ IDADE } \\
\hline & 0 a 3 anos & 4 a 7 anos & 8 a 11 anos & $\begin{array}{c}12 \text { a } 15 \\
\text { anos }\end{array}$ & $\begin{array}{c}16 \text { a } 18 \\
\text { anos }\end{array}$ \\
\hline 1 - Atentado Violento ao Pudor* & 3 & 19 & 14 & 7 & 1 \\
\hline 2 - Ato Obsceno & - & - & - & 1 & - \\
\hline 3 - Art. 241 do ECA & - & - & - & 1 & - \\
\hline 4 - Art. 244 - A do ECA & - & - & - & 2 & 2 \\
\hline 5 - Estupro & - & 1 & 3 & 7 & 2 \\
\hline 6 - Estupro Tentado & - & 1 & - & 2 & 1 \\
\hline 7 - Estupro Presumido & - & - & - & 3 & - \\
\hline 8 - Importunação Ofensiva ao Pudor & - & 1 & - & 1 & - \\
\hline 9 - Roubo com Estupro & - & - & - & 1 & - \\
\hline 10 - Art. 243 do ECA e Atentado Violento ao Pudor & - & - & - & 1 & - \\
\hline 11- Art. 243 do ECA e Estupro & - & - & - & 1 & - \\
\hline TOTAL* & 3 & 21 & 17 & 27 & 6 \\
\hline$\%$ & 4,05 & 28,38 & 22,97 & 36,49 & 8,11 \\
\hline
\end{tabular}

Nota: *Nessa tabela, foram analisados 71 processos, pois há um processo que não foi encontrado e outro em que não constava o depoimento, completando, assim, os 73 crimes sexuais cometidos contra a criança e o adolescente, como referido anteriormente. Esses processos não encontrados se referem a Atentado Violento ao Pudor e Estupro.

*No caso do crime de Atentado Violento ao Pudor, existem processos em que há mais de uma vítima, somando um total de 74 vítimas.

Fonte: Dados da pesquisa.

que ocorreram as denúncias. Porém, mesmo as adolescentes assumindo que gostavam do namorado maior de idade e que permitiram que ocorresse sexo entre eles, elas não respondem por si mesmas nos casos expressos em lei por serem menores de idade e o ato sexual configura-se em estupro. De acordo com o ECA, art. $2^{\circ}$,considera-se criança a pessoa até 12 anos de idade incompletos e, adolescente aquela entre 12 e 18 anos de idade. Tal artigo possui um parágrafo único que ressalta: nos casos expressos em lei, aplica-se excepcionalmente este Estatuto às pessoas entre 18 e 21 anos de idade.

A idade entre 4 e 7 anos apresenta o segundo maior índice, $28,38 \%$, seguida pelos $22,97 \%$ referente à idade entre 8 a 11 anos. No segundo maior índice, a maior parte dos crimes sexuais refere-se a atentado violento ao pudor e aconteceram com crianças pequenas que muitas vezes não sabem diferenciar o tipo de carinho que estão recebendo ou, como já dito anteriormente, se encantam com as promessas de presentes, brinquedos ou objetos que seus pais muitas vezes não lhes proporcionam.

Nesse sentido, é importante compreender que, no ato sexual, de acordo com Furniss (1993), o adulto projeta seus desejos sexuais na criança. As atividades sexuais entre adultos e crianças ocorrem para satisfazer os desejos sexuais unicamente do adulto e não em resposta às necessidades da criança. A criança pré-pubere jamais poderá dar o consentimento informado para a prática sexual, razão pela qual não deve ser em momento algum corresponsabilizada pela situação abusiva.

Obtivemos, no Quadro 5, uma diferença significativa entre crimes sexuais cometidos contra o sexo feminino e crimes sexuais cometidos contra o sexo masculino. Temos consideráveis $77,03 \%$ de crimes sexuais ocorridos contra o sexo feminino e $22,97 \%$ ocorridos contra o sexo masculino. 
Quadro 5 - Tipos de crimes sexuais cometidos contra a criança e o adolescente em relação ao sexo das vítimas

\begin{tabular}{lcc}
\multicolumn{1}{c}{ Tipos de crimes sexuais cometidos contra a criança } & SEXO \\
\cline { 2 - 3 } & Masculino & Feminino \\
\hline 1- Atentado Violento ao Pudor* & 15 & 28 \\
\hline 2 - Ato Obsceno & - & 1 \\
\hline 3 - Art. 241 do ECA & - & 1 \\
\hline 4 - Art. 244 - A do ECA & - & 4 \\
\hline 5 - Estupro & - & 13 \\
\hline 6 - Estupro Tentado & - & 4 \\
\hline 7 - Estupro Presumido & - & 3 \\
\hline 8 - Importunação Ofensiva ao Pudor & 1 & 1 \\
\hline 9 - Roubo com Estupro & - & 1 \\
\hline 10 - Art. 243 do ECA e Atentado Violento ao Pudor & 1 & - \\
\hline 11 - Art. 243 do ECA e Estupro & - & 1 \\
\hline
\end{tabular}

Nota: *Foram analisados, nesta tabela, 71 processos, pois há um processo que não foi encontrado e outro em que não constava o depoimento, completando, assim, 73 crimes sexuais cometidos contra a criança e o adolescente. Eles se referem a Atentado Violento ao Pudor e Estupro.

*No caso do crime de Atentado Violento ao Pudor, existem processos onde há mais de uma vítima, completando um total de 74 vítimas.

Fonte: Dados da pesquisa.

Observamos, a partir desses valores, que ocorre a chamada violência de gênero. Segundo Strey (2004), violência de gênero é aquela que incide, abrange e acontece porque alguém é homem ou mulher. Mesmo que a violência de gênero possa ocorrer entre homens e mulheres, estudos e estatísticas mostram que a maioria da violência de gênero é cometida sobre mulheres pelos homens e obtêm consequências físicas e psicológicas consideradas mais graves para as mulheres.

A violência de gênero, de acordo com Saffiotti (2004), engloba tanto a violência de homens contra mulheres quanto a violência de mulheres contra homens, sendo, assim, o conceito de violência de gênero um conceito aberto. 0 que leva, portanto, ao conceito de patriarcado que indica o regime da dominação-exploração das mulheres pelos homens. Dessa forma, a violência de gênero não ocorre aleatoriamente, mas faz parte de uma construção social de gênero que privilegia o masculino.
Strey (2004) relata também que as mulheres são as maiores vítimas de violência de gênero, inclusive historicamente; não conceituando que são vítimas passivas ou submissas, e sim preferidas nas culturas patriarcais. Dessa forma, a violência de gênero torna-se quase que um sinônimo de violência contra a mulher.

0 Quadro 6 refere-se às pessoas que levam a vítima para realizar a denúncia. Familiares ou desconhecidos que optam por acabar com o sofrimento da vítima ou com seu próprio sofrimento quando conseguem denunciar abusadores que fazem parte da própria família ou de um relacionamento amoroso. Observa-se, no Quadro 6, que as mães aparecem como as mais presentes no ato de realizar a denúncia. São significativos $46,48 \%$, seguidos pelos pais que possuem $16,90 \%$. Também observamos a atuação do Conselho Tutelar que, sozinho ou acompanhado das mães, realizam ao total $15,49 \%$, zelando pelos direitos das crianças e adolescentes (Conselho Municipal, 2003). 
Quadro 6 - Tipos de crimes sexuais cometidos contra a criança e 0 adolescente considerando quem levou a vítima para realizar a denúncia

\begin{tabular}{|c|c|c|c|c|c|c|c|c|c|c|c|}
\hline \multirow{2}{*}{$\begin{array}{c}\text { Tipos de crimes sexuais } \\
\text { cometidos contra a criança } \\
\text { e o adolescente }\end{array}$} & \multicolumn{11}{|c|}{ Quem levou a vítima para realizar a denúncia } \\
\hline & M̃̃e & $\begin{array}{c}\text { Mãe e } \\
\text { Conselho }\end{array}$ & Pai & Avó & AŶ & Tin & Tin & Irm $\tilde{~}$ & Conselho & Polícia & Outro \\
\hline 1 - Atentado Violento ao Pudor & 20 & 2 & 5 & 3 & 2 & _- & 2 & 1 & 3 & - & 2 \\
\hline 2 - Ato Obsceno & - & - & 1 & - & - & - & - & - & - & - & - \\
\hline 3 - Art. 241 do ECA & 1 & - & - & - & - & - & - & - & - & - & - \\
\hline 4 - Art. 244 - A do ECA & 1 & - & - & 1 & - & - & - & - & 2 & - & - \\
\hline 5 - Estupro & 6 & 1 & 3 & - & - & 1 & - & - & 2 & - & - \\
\hline 6 - Estupro Tentado & 1 & - & 1 & - & - & - & - & 1 & - & 1 & - \\
\hline 7 - Estupro Presumido & 1 & 1 & 1 & - & - & - & - & - & - & - & - \\
\hline $\begin{array}{l}8 \text { - Importunação Ofensiva ao } \\
\text { Pudor }\end{array}$ & 1 & - & 1 & - & - & - & - & - & - & - & - \\
\hline 9 - Roubo com Estupro & - & - & - & - & - & - & - & - & - & 1 & - \\
\hline $\begin{array}{l}10 \text { - Art. } 243 \text { do ECA e Atentado } \\
\text { Violento ao Pudor }\end{array}$ & 1 & - & - & - & - & - & - & - & - & - & - \\
\hline 11- Art. 243 do ECA e Estupro & 1 & - & - & - & - & - & - & - & - & - & - \\
\hline TOTAL* & 33 & 4 & 12 & 4 & 2 & 1 & 2 & 2 & 7 & 2 & 2 \\
\hline$\%$ & 46,48 & 5,63 & 16,90 & 5,63 & 2,82 & 1,41 & 2,82 & 2,82 & 9,86 & 2,82 & 2,82 \\
\hline
\end{tabular}

Nota: *Há um processo que não foi encontrado e outro em que não constava o depoimento, completando, assim, 73 crimes sexuais cometidos contra a criança e o adolescente. Eles se referem a Atentado Violento ao Pudor e Estupro.

Fonte: Dados da pesquisa.

Quem leva a criança e/ou adolescente para realizar a denúncia, segundo Volnovich (2005), acaba por quebrar o "muro do silêncio" onde, por vezes, se "acomodou". Há uma revitimização do familiar que realizou a denúncia. Por ser adulto, ocorre no imaginário de profissionais da saúde mental, da justiça e do julgamento popular que, de alguma forma, há um grau de responsabilidade do denunciante quando o abuso é intrafamiliar e isso acaba por desqualificar o seu relato. Muitas vezes os denunciantes, em algum momento, desejam se calar e, dessa forma, o que se revela como indicador da ocorrência do abuso sexual é exatamente a persistência na denúncia. 0 que ocorre é que o familiar que realiza a denúncia a faz, na maioria das vezes, a partir do relato da criança que sofreu o abuso, ajudando-a a colocar em palavras o que aconteceu, desta forma, a denúncia pode por vezes ser desqualificada pela hipótese de que houve indução por parte do familiar.

Furniss (1993) relata que, nos casos em que o segredo é mantido, ocorre uma falha na função protetora do progenitor que não é o abusador. A mãe torna-se uma cúmplice silenciosa do abuso, pois ela acaba por se colocar ao lado do abusador. Porém, quando existe uma relação próxima e protetora entre mãe e filha, o abuso, mesmo ocorrendo, não se mantém por muito tempo, pois essa mãe perceberá os sinais do abuso na criança e as mudanças na dinâmica familiar.

Esse mesmo autor revela que existem casos em que a mãe é realmente cúmplice no abuso e se utiliza deste para regular os conflitos familiares. A mãe abre mão de suas obrigações conjugais e por vezes considera justo que a filha se sacrifique para contribuir na manutenção da família, mantendo o pai/ esposo no núcleo familiar sem que haja necessidade deste buscar fora de casa uma parceira sexual.

De acordo com Dobke (2001), quando a família revela o abuso, ela acaba por entrar em crise, pois a revelação do segredo desestabiliza o sistema familiar. 0 que pode ocorrer é que com a revelação a família tente desqualificar o relato e a própria vítima a fim de obter o equilíbrio que existia anteriormente. Nesse sentido, pode surgir uma pressão por parte da família sobre a vítima a fim de retomar o funcionamento familiar, o que pode justificar as 
retratações que ocorrem em alguns casos (Viaux, 1997; Arpini et al., 2008).

Rangel (2002) aponta dois fatores ligados à recorrência do abuso entre pai e filha. 0 primeiro condiz com a assimetria nos relacionamentos familiares, em que os pais são frutos do sexismo e a relação com seus filhos provinda ainda da concepção de criança como objeto e não como sujeito; também a vergonha em torno do abuso tornando-o tabu para a revelação e deixando-o como segredo. O segundo é justamente a simetria entre o homem e a mulher e entre estes e seus filhos, com envolvimento afetivo e sentimento de proteção maiores que, mesmo não sendo impeditivos do abuso, são fatores que dificultam sua sustentação como segredo e sua continuidade por toda a infância e/ou adolescência da vítima.

Essa mesma autora relata que, ao manter o segredo e se adaptar à situação, a criança começa a se sentir cúmplice do agressor. Assim surge o sentimento de culpa graças à criança ter se sentido participante do abuso. Esse sentimento explica a baixa autoestima e os traumas que permanecem na vida adulta. 0 segredo como característica específica do abuso sexual intrafamiliar registra a diferença entre ele e outras formas de violência sofridas na infância, explicando assim, suas consequências tão prejudiciais. A manutenção desse segredo possui causas internas e externas no núcleo familiar. A estigmatização social, as dificuldades materiais e emocionais, como o divórcio, o fato da criança se sentir culpada pela prisão do pai, o medo do abandono, entre outros, são motivos que levam as crianças e a família a manter o segredo em relação ao abuso (Viaux, 1997; Arpini et al., 2008). Assim, percebe-se a dificuldade da revelação, não só conscientemente, mas principalmente em uma atuação inconsciente. Revelar esse segredo é sinônimo de desestabilização familiar, que traz consigo um sentimento de vergonha e culpa dentro dos conceitos culturais. Dessa forma, é passível pensar em ocorrências muito maiores de crimes sexuais e que não chegam à delegacia ou ao conhecimento popular.

\section{Considerações finais}

A partir da pesquisa que foi realizada, percebemos o quanto os direitos de crianças e adolescentes ainda são violados. Elas ainda são focos de violência física, psicológica e sexual. A imaturidade cognitiva e, na maioria das vezes, a confiança depositada no adulto resultam na facilidade para que aconteça o engano, o convencimento e a submissão. O poder do outro (adulto, mais forte, maior) é usado para ultrapassar os limites e assim violentar os direitos de crianças e adolescentes. Muitas vezes eles são incumbidos a não falar, e o sofrimento toma dimensões cada vez maiores. É nessa esfera de sofrimento que os crimes sexuais foram expostos nesta pesquisa. Os números totais dos crimes trazem à tona uma verdade que é escondida ou, melhor dizendo, camuflada.

Os crimes sexuais contra crianças e adolescentes revelam o uso indevido do poder do outro. E esse outro se revela na maioria das vezes próximo da vítima, fazendo parte de seu grupo de relações, ou seja, pai, avós, tios, padrastos, primos, vizinhos que quebram.

0 artigo número 15 do Estatuto da Criança e do Adolescente define que crianças e adolescentes possuem direito à liberdade, ao respeito e à dignidade como pessoas em desenvolvimento e como sujeitos de direitos civis, humanos e sociais que as leis e a Constituição garantem. Porém os que deviam amparar acabam por desproteger e esses direitos deixam de serem garantidos. Não cabe aqui falar apenas que faltam políticas públicas; a dimensão de tudo isso é muito maior. Podemos falar em consciência. Talvez não a consciência apenas de quem pratica o ato incestuoso ou o abuso sexual, mas a consciência em relação à denúncia e sua importância, assim como da proteção à quem denuncia, e também da necessidade do tratamento psicológico, e com isso da elaboração do sofrimento.

Como se pode perceber por meio dos dados da pesquisa, as crianças e os adolescentes não estão sendo respeitados em sua inviolabilidade física, psíquica e moral, como define o artigo 17 do Estatuto da Criança e do Adolescente. Nesta pesquisa, tratamos apenas de casos de abuso sexual, mas tem-se também outros vários crimes cometidos contra a criança e o adolescente. Violência, abandono, negligência, entre outros, os deixam desprotegidos e, na maioria das vezes cria-se um círculo vicioso nos crimes contra a criança e o adolescente.

Por isso, não podemos deixar que esses crimes continuem acontecendo contra as crianças e os adolescentes. É preciso que haja políticas públicas efetivas, mas também é preciso consciência para a 
denúncia, consciência do sofrimento das vítimas e proteção para quem toma a decisão e tem a coragem de denunciar. Assim, abrem-se caminhos para o desenvolvimento de inúmeras outras pesquisas. Aqui, apenas o primeiro passo foi dado, com o intuito de demonstrar que os crimes contra a criança e adolescentes ocorrem e que não são poucos.

Crianças e adolescentes que precisam falar, mas se calam diante da situação do depoimento que precisa ser dado. Talvez por medo, por vergonha ou por estar realmente sofrendo. Aqui se deve pensar em outras maneiras de escutar as vítimas. Não fazer com que o depoimento seja realizado inúmeras vezes para diferentes profissionais ou até mesmo na frente do acusado. Não posso falar aqui em testemunho sem danos, pois acredito que todo o testemunho trará algum tipo de dano para a vítima, pois esta precisa reviver a situação do abuso sexual que já lhe causou tanto sofrimento. Mas podemos falar em um testemunho que traga também o suporte que a vítima está precisando. 0 apoio dos familiares, o sigilo do seu depoimento, uma escuta atenta e profissional e um tratamento psicológico para a vítima e seus familiares poderem lidar números quantificados trazem esse apelo. Mas, com certeza, o apelo maior vem das vítimas; estas esperam ansiosas e com sofrimento pelas mudanças.

\section{Referências}

Ariès, P. (1981). História social da criança e da família (D. Flaksman Trad.). Rio de Janeiro: LTC. (Originalmente publicado em 1960).

Arpini, D. M., Soares, A. C., Berte, L., \& Forno, C. D. (2008). A revelação e a notificação das situações de violência contra a infância e a adolescência. Psicologia em Revista, 14(2), 95-112.

Arpini, D. M., Hermann, C., Forno, C. D., \& Soares, A. C. (2010). A importância da escuta na revelação da violência contra a infância e a adolescência. Psicologia, Educação e Cultura, 14(1), 111-128.

Bardin, L. (1997). Análise de conteúdo. Lisboa: Edições 70.

Conselho Municipal dos Direitos da Criança e do Adolescente. (2003). Estatuto da Criança e do Adolescente (ECA). Lei Federal n. 8.069/1990. Santa Maria: Pallotti.
Dobke, V. (2001). Abuso sexual: A inquirição das crianças, uma abordagem interdisciplinar. Porto Alegre: Ricardo Lenz.

Faleiros, V. de P., \& Faleiros, E. T. S. (Coord.). (2001). Circuito e curtos-circuitos: Atendimento, defesa e responsabilidade do abuso sexual contra crianças e adolescentes no Distrito Federal. São Paulo: Veras.

Ferenczi, S. (1992). Confusão de língua entre os adultos e a criança. In S. Ferenczi. Psicanálise IV. (pp. 97-106). São Paulo: M. Fontes.

Franco, A. S. (2005). Crimes hediondos (5a ed.). São Paulo: Revista dos Tribunais.

Freitas, M. C. de (Org.). (1997). História social da infância no Brasil (2a ed.). São Paulo: Cortez.

Furniss, T. (1993). Abuso sexual da criança. Porto Alegre: Artes Médicas.

Gabel, M. (1997). Algumas observações preliminares. In M. Gabel (Ed.). Crianças vítimas de abuso sexual (pp. 9-13). São Paulo: Summus.

Gil, A. C. (1991). Como elaborar projetos de pesquisa. São Paulo: Atlas.

Guerra, V. N. de A. (1998). Violência de pais contra filhos: A tragédia revisitada (3a ed.). São Paulo: Cortez.

Jaeger, F. P. (2004). Infância, violência e relações de gênero. In M. N. Strey, M. P. R. Azambuja, \& F. P. Jaeger (Org.). Violência, gênero e políticas públicas (pp. 291-315). Porto Alegre: EDIPUCRS.

Lamour, M. (1997). Os abusos sexuais em crianças pequenas: Sedução, culpa e segredo. In M. Gabel (Org.). Crianças vítimas de abuso sexual (pp. 43-61). São Paulo: Summus.

Marcílio, M. L. (1998). História social da criança abandonada. São Paulo: Hucitec.

May, T. (2004). Pesquisa social: Questões, métodos e processo (3. ed.). Porto Alegre: Artmed.

Mess, L. A. (2001). Abuso sexual: Trauma infantil e fantasias femininas. Porto Alegre: Artes e Ofícios.

Rangel, P. C. (2002). Abuso sexual intrafamiliar recorrente. Curitiba: Juruá. 
Rouyer, M. (1997). As crianças vítimas, consequências a curto e médio prazos. In M. Gabel (Ed.). Crianças vítimas de abuso sexual (pp. 62-71). São Paulo: Summus.

Saffioti, H. I. B. (2004). Gênero, patriarcado e violência. São Paulo: Fundação Perseu Abramo.

Strey, M. N. (2004). Violência de gênero: Uma questão complexa e interminável. In M. N. Strey, M. P. R. Azambuja, \& F. P. Jaeger (Org.). Violência, gênero e políticas públicas (pp. 13-43). Porto Alegre: EDIPUCRS.
Viaux, J. (1997). Nem muito, nem pouco. Exatamente o necessário. In M. Gabel (Ed.). Crianças vítimas de abuso sexual (pp. 121-131). São Paulo: Summus.

Volnovich, J. (2005). Abuso sexual na infância. Rio de Janeiro: Lacerda.

Vorcaro, A. M. R. (2004). A criança na clínica psicanalítica. Rio de Janeiro: Companhia de Freud. 